\title{
A IMPORTÂNCIA DOS JOGOS E BRINCADEIRAS NO DESENVOLVIMENTO
} INFANTIL

Luciane Dantas Rodriguez

Pedagoga e Professora de Educação Infantil

\section{RESUMO}

O presente trabalho apresenta uma revisão bibliográfica sobre a importância do brincar no desenvolvimento infantil. Ressaltando a importância dos jogos e brincadeiras para a aprendizagem das crianças. O brincar permite à criança resolver conflitos internos, além de garantir a construção do conhecimento e do desenvolvimento emocional, cognitivo e social. É a oportunidade que a criança tem de aprender sozinha com sua própria falha sem se sentir constrangida em errar e tentar novamente.

Palavras chaves: Brincar, brincadeira, desenvolvimento. 


\section{Introdução}

Esse artigo tem por objetivo mostrar a importância do brincar para o desenvolvimento infantil. Seu objeto de estudo é elucidar as contribuições que a brincadeira pode oferecer à aprendizagem e ao desenvolvimento infantil. Para tanto, primeiramente é feita uma pesquisa bibliográfica sobre a utilização das definições dos termos brinquedo, brincadeira e jogo. A brincadeira é vista na literatura como um recurso que pode estimular o desenvolvimento infantil e proporcionar meios facilitadores para a aprendizagem.

Este artigo justifica-se por que o brincar é a atividade predominante na infância e vem sendo explorado no campo científico, com o intuito de caracterizar as suas peculiaridades, identificar as suas relações com o desenvolvimento e com a saúde e, entre outros objetivos, intervir nos processos de educação e de aprendizagem das crianças. A metodologia utilizada será a qualitativa, através da pesquisa bibliográfica.

O artigo subdividiu-se em três subitens, iniciando pela evolução histórica do brincar, o jogo e o brinquedo e por fim, a brincadeira e sua importância. 


\section{A EVOLUÇÃO HISTÓRICA DO BRINCAR}

Os primeiros estudos sobre a prática do jogo ou do lúdico comprovam que seu uso vem desde a pré-história, com as atividades de caça, pesca, dança e luta que não se restringem somente ao caráter da sobrevivência, passada de geração em geração. $\mathrm{Na}$ Grécia e em Roma o jogo ganha um novo sentido lúdico. Para Platão, o "aprender brincando" é importante e contrapõe a utilização da violência e da repressão. Já Aristóteles propõe o uso de jogos que imitem atividades sérias dos adultos para a educação de crianças pequenas, visando um preparo para a vida adulta. Mas ainda, nessa época, não era discutido o uso do jogo como recurso auxiliar para o ensino.

Os romanos utilizavam os jogos para o preparo físico, visando formar soldados e cidadãos obedientes. Na Grécia os jogos eram influenciados pela cultura física, formação estética e espiritual.

Segundo Kishimoto:

“(...) A prática de aliar o jogo aos primeiros estudos parece justificar o nome de ludos atribuído às escolas responsáveis pela instituição elementar, semelhante aos locais destinados a espetáculos e à prática de exercícios de fortalecimento do corpo e do espírito." (apud kishimoto, 1994: p.15).

Devido ao Cristianismo os jogos passaram a ser considerados profanos, imoral e sem nenhuma significação, pelo fato da sociedade cristã estabelecer uma educação disciplinar, valorizando a memorização e a obediência.

Novas concepções pedagógicas surgem na época do Renascimento, resgatando o jogo e incorporando ao cotidiano dos jovens como uma ação natural do ser humano e não como diversão. A partir daí, nascem os jogos educativos, visando o desenvolvimento do ser humano.

Já no século XVIII, com o surgimento do movimento científico, são diversificados os jogos, que são criados para o ensino de ciências para príncipes e nobres, vindo a ser popularizados posteriormente. 
Devido à expansão dos jogos ao longo dos tempos, crescem experiências que colocam o jogo como facilitador das tarefas de ensino, assim como o próprio nome diz: “(...) jogo educativo, metade jogo e metade educação (...)” ( Kishimoto, 1994: p. 18).

O jogo Educativo apresenta duas funções concomitantes, dois elementos distintos, conforme descrito por Kishimoto:

"1.função lúdica - o jogo propicia a diversão, o prazer e até o desprazer quando escolhido voluntariamente, e 2. Função educativa - o jogo ensina qualquer coisa que complete o indivíduo em seu saber, seus conhecimentos e sua apreensão do mundo (...)" ( Kishimoto, 1994: p.19).

Atualmente, alguns teóricos e filósofos apontam um desequilíbrio dessas funções, pois se ocorrer a predominância da função lúdica não há o ensino e se houver a predominância da função educativa existirá só o ensino, portanto, o objetivo maior do jogo educativo é o equilíbrio entre essas funções, agindo como um suporte na ação pedagógica intencional do professor e no respeito e liberdade à ação voluntária da criança.

\subsection{O Jogo e o Brinquedo}

Há alguns anos atrás o jogo era visto como algo inútil e a partir do Romantismo, o jogo vem sendo considerado como algo sério e importante para o desenvolvimento da criança. Não existe uma definição correta para explicar o significado do que é o jogo. Cada lugar e cada sociedade constrói sua concepção de jogo, dependente de seus valores, modo de vida, modo de pensar que é expresso através da linguagem de cada contexto social.

O jogo é uma ação que a criança estabelece com o meio, a fim de satisfazer suas vontades e sentir prazer naquilo que faz, sempre de acordo com cada cultura. Por exemplo: uma criança de uma tribo indígena que atira o arco e a flecha em animais é considerado por algumas pessoas como jogo e para ela é um preparo profissional do que depende a sua subsistência.

“(...) Uma mesma conduta pode ser jogo ou nãojogo em diferentes culturas, dependendo do significado a ela atribuído. Por tais razões fica difícil elaborar uma definição de jogo que englobe a multiplicidade de suas manifestações 
concretas. Todos os jogos possuem peculiaridades que os aproximam ou distanciam" (apud Kishimoto, 2005: p.15)

A partir disso, o que diferencia o jogo em cada lugar são as diferentes culturas e os objetos que os caracterizam, tais objetos como, o uso de peças que podem ser feitas de papelão, madeira, plástico, pedra ou metais.

Para entender melhor o jogo é indispensável conhecer o significado do brinquedo, onde a criança mantém uma relação íntima com o objeto sem a determinação de regras para a sua utilização.

Ao brincar com uma boneca, a criança tem várias possibilidades de brincar, desde a manipulação até a realização de brincadeiras como "mamãe e filhinha" podendo representar aspectos da realidade, ao contrário do jogo de xadrez, em que a criança desempenha certas habilidades definidas por suas regras.

O brinquedo permite a representação da realidade, proporcionando a manipulação deste, para que a criança possa vivenciar o mundo dos adultos através da imaginação.

Segundo Piaget, o mundo existe para a criança na medida em que lhe é possível jogar com ele, extraindo dos objetos possibilidades de prazer e harmonia. O jogo seria, então, a forma de interação por excelência da criança com seu entorno; sem ele, não havendo, inclusive, condições suficientes para que esta interação ocorra.

No jogo, a criança se encontra num clima lúdico, dentro do qual a realidade tem conteúdo e simbologia próprios. Sua importância é muito grande, porque a criança constrói seu próprio mundo através dessas atividades.

O desenvolvimento das atividades lúdicas deve-se ao brinquedo, que é objeto facilitador, que desperta curiosidade, a imaginação e a invenção.

É assim que cabos de vassoura tornam-se cavalos e com eles as crianças cavalgam para outros lugares; pedaços de pano transformam-se em capas e vestimentas de príncipes e princesas; pedrinhas em comidinhas; cadeiras e bancos em trens; crianças em pais, professores, motoristas, monstros, entre outros.

Os jogos e brincadeiras não ficam restritos somente ao mundo das emoções e da sensibilidade, mas também exercita a inteligência, evolução do pensamento e de todas as funções mentais. 


\subsubsection{O Objeto Lúdico}

Brinquedo, brincadeira e jogo são termos que podem se confundir, uma vez que a sua utilização varia de acordo com o idioma utilizado. Kishimoto (1994), discute as dificuldades existentes na definição dessas palavras nas línguas francesa, inglesa e portuguesa. Segundo os autores, cada idioma possui particularidades na utilização das mesmas, o que as faz diferirem entre si

Para a caracterização do objeto lúdico, cada idioma possui um termo próprio, que identifica e designa o material concreto utilizado na brincadeira infantil. $O$ vocábulo brinquedo, utilizado no português, é jouet no francês e toy na língua inglesa, com clara distinção semântica.

Quanto à designação dos verbos brincar e jogar, existem dificuldades na sua utilização. Enquanto no português há uma definição que distingue as duas ações, no inglês e no francês ambas têm diversos significados, muitos dos quais diferentes da ação lúdica infantil. No inglês, o termo game designa o ato de jogar e se refere mais especificamente aos jogos de regras, entretanto, ele pode se confundir e ter o mesmo significado de play, que indica o brincar, a ação da brincadeira. A língua francesa designa o termo jouer para as ações de brincar e de jogar, não fazendo distinção semântica entre elas. Tanto no inglês quanto no francês, os vocábulos que designam as ações de brincar e de jogar também têm outros significados. Eles também podem ser utilizados para tarefas como representar, tocar instrumentos e uma gama imensa de atividades, diferentes da ação lúdica infantil.

A palavra em português que indica a ação lúdica infantil é caracterizada pelos verbos brincar e jogar, sendo que brincar indica atividade lúdica não estruturada e jogar, atividade que envolve os jogos de regras propriamente ditos. Baptista da Silva (2003) afirma que os verbos brincar e jogar, em português, não têm significados tão amplos quanto os seus correspondentes em inglês e francês. A mesma autora aborda que, no cotidiano da língua portuguesa, os verbos brincar e jogar também podem ter outros sentidos, entretanto, seu significado principal está relacionado à atividade lúdica infantil. Ainda na língua portuguesa, existe uma falta de discriminação na utilização dos termos brincar e jogar. Mesmo estando o termo jogar diferenciado de brincar pelo aparecimento das regras, a utilização de ambos, muitas vezes, se confunde.

\subsection{A Brincadeira e sua importância}

Numa sociedade desigual, as crianças desempenham, nos diversos contextos, papéis diferentes. A ideia de infância moderna foi universalizada com base em um padrão de crianças das classes médias, a partir de critérios de idade e de dependência do adulto, característicos de sua inserção no interior dessas classes. No entanto, é preciso considerar a diversidade de aspectos sociais, culturais e políticos: no Brasil, as nações 
indígenas, suas línguas e seus costumes; a escravidão das populações negras; a opressão e a pobreza de expressiva parte da população; o colonialismo e o imperialismo que deixaram marcas diferenciadas no processo de socialização de crianças e adultos

Nos relatos sobre a brincadeira infantil Vygotsky (1991) afirma que esta é uma situação imaginária criada pela criança e onde ela pode, no mundo da fantasia, satisfazer desejos até então impossíveis para a sua realidade. Portanto, o brincar "é imaginação em ação" (FRIEDMANN, 1996). Para Vygotsky (1991) a brincadeira nasce da necessidade de um desejo frustrado pela realidade. Elkonin (1998) amplia essa sentença quando afirma que os objetos, ao terem seus significados substituídos, transformam-se em signos para a criança. Desta forma, "a criança não faz distinção entre o brinquedo e o que ele significa, mas a utilidade que terá nas representações que serão feitas com ele" (BISCOLI, 2005; p. 29).

Vygotsky (1991) também afirma que a brincadeira, mesmo sendo livre e não estruturada, possui regras. Para o autor todo tipo de brincadeira está embutido de regras, até mesmo o faz-de-conta possui regras que conduzem o comportamento das crianças. Uma criança que brinca de ser a mamãe com suas bonecas assume comportamentos e posturas pré-estabelecidas pelo seu conhecimento de figura materna. Para Vygotsky (1991) o brincar é essencial para o desenvolvimento cognitivo da criança, pois os processos de simbolização e de representação a levam ao pensamento abstrato. Elkonin (1998) avançando nos estudos de Vygotsky elaborou a lei do desenvolvimento do brinquedo. Para este autor o brincar passa por momentos evolutivos. A brincadeira vai de uma situação inicial, onde o papel e a cena imaginária são explícitos e as regras latentes, para uma situação em que as regras são explícitas e o papel e a cena imaginária latentes.

Recentemente, imagens de pobreza de crianças e trabalho infantil retratam uma situação em que o reino encantado da infância teria chegado ao fim, ocasionando o desaparecimento da infância.

A criança pelo fato de se situar em um contexto histórico e social, ou seja, em um ambiente estruturado a partir de valores, significados, atividades e artefatos construídos e partilhados pelos sujeitos que ali vivem, incorpora a experiência social e cultural do brincar por meio das relações que estabelece com os outros - adultos e crianças. Mas a experiência não é simplesmente reproduzida, e sim recriada a partir do que a criança traz de novo, com o seu poder de imaginar, criar, reinventar e produzir cultura.

Entretanto, os estudos da psicologia baseados em uma visão histórica e social dos processos de desenvolvimento infantil apontam que o brincar é um importante processo psicológico, fonte de desenvolvimento e aprendizagem.

De acordo com Vygotsky (1997), um dos principais representantes dessa visão, o brincar é uma atividade humana criadora, na qual imaginação, fantasia e realidade 
interagem na produção de novas possibilidades de interpretação, de expressão e de ação pelas crianças, assim como de novas formas de construir relações sociais com outros sujeitos, crianças e adultos. Tal produção não se faz passivamente, mas mediante um processo ativo de reinterpretação do mundo, que abre lugar para a invenção e a produção de novos significados, saberes e práticas. A partir disso, Vygotsky defende que novos significados são elaborados, novos papéis sociais e ações sobre o mundo são desenhados e novas regras e relações entre os objetos e os sujeitos, entre si, são instituídas.

Com a chegada da globalização, com a mídia, internet, o acesso das crianças à informação adulta teria terminado por expulsá-las do jardim da infância. As crianças atualmente não têm espaços livres e nem locais adequados para brincar. Na maioria das vezes, elas vivem absorvidas numa atitude estática em frente à televisão, computador e variados tipos de brinquedos eletrônicos.

É fundamental que a escola resgate e valorize atividades que irão proporcionar às crianças momentos inesquecíveis de sua infância, que são as brincadeiras infantis. Estes tipos de atividades desenvolvem a criatividade, psicomotricidade e a socialização integral.

O brincar constitui-se uma forma importantíssima na formação da criança, pois é uma atividade espontânea, natural e necessária ao seu desenvolvimento.

É importante ressaltar que a brincadeira não é algo já dado na vida do ser humano, ou seja, aprende-se a brincar, desde cedo, nas relações que os sujeitos estabelecem com os outros e com a cultura, sendo essencial à saúde física, emocional e intelectual das crianças. As brincadeiras também são formas de transmitir valores, costumes e ensinamentos

A brincadeira é a atividade principal da infância. Essa afirmativa se dá não apenas pela frequência de uso que as crianças fazem do brincar, mas principalmente pela influência que esta exerce no desenvolvimento infantil. Vygotsky (1991) ressalta que a brincadeira cria as zonas de desenvolvimento proximal e que estas proporcionam saltos qualitativos no desenvolvimento e na aprendizagem infantil. Leontiev (1994) amplia esta teoria afirmando que durante a brincadeira ocorrem as mais importantes mudanças no desenvolvimento psíquico infantil. Para estes autores a brincadeira é o caminho de transição para níveis mais elevados de desenvolvimento.

A característica social, de acordo com a perspectiva sociocultural, é vista como a mola propulsora para o desenvolvimento infantil. Leontiev (1994) afirma que na atividade lúdica a criança descobre as relações existentes entre os homens. Além disso, as crianças também conseguem, através da brincadeira, avaliar suas habilidades e compará-las com as das outras crianças. A brincadeira também permite à criança a se apropriar de códigos culturais e de papéis sociais. 
O autor relata que os brinquedos mudam conforme mudam os padrões de uma sociedade. Para constatar isto basta fazer uma análise a respeito das características dos brinquedos utilizados pelas crianças de 40 ou 50 anos atrás. A boneca por exemplo, ainda é utilizada pelas crianças da atualidade, contudo, este objeto passou por mudanças significativas em sua confecção, material utilizado, formas e atribuições. Enquanto que a maioria das bonecas de 50 anos atrás era construída de porcelana, pano ou palha de milho e com características infantilizadas, as bonecas atuais têm as mais diversificadas matérias primas, suas formas imitam o padrão de beleza estipulado pela sociedade (jovem, alta e esguia), além das inúmeras características extras das quais são dotadas, tais como falar, andar, dançar, cantar, etc. Independentemente do tipo ou das características do brinquedo, pelo brincar o desenvolvimento infantil está sendo estimulado (VYGOTSKY, 1991).

As primeiras brincadeiras do bebê, que são caracterizadas pela observação e posterior manipulação de objetos, oferecem à criança o conhecimento e a exploração do seu meio através dos órgãos dos sentidos. Leontiev (1994) afirma que as brincadeiras mudam conforme muda a idade das crianças. Logo que a criança começa a falar os jogos de exercícios começam a diminuir e dão espaço aos jogos simbólicos.

Para Vygotsky (1991) as crianças querem satisfazer certos desejos que muitas vezes não podem ser satisfeitos imediatamente. Desta forma, pelo faz de conta, a criança testa e experimenta os diferentes papéis existentes na sociedade (papai, mamãe, filhinho, trabalhador, etc.).

Próximo ao final desta fase, os jogos simbólicos começam a declinar porque passam a aproximar-se cada vez mais do real. O símbolo perde seu caráter de deformação lúdica e passa a ser uma representação imitativa da realidade. Inicia-se então a estrutura dos jogos de regras, que têm um ponto de partida próximo aos 6 anos e vai até o início da adolescência. Para Vygotsky (1991) todas as modalidades de brincadeiras estão inseridas de regras e de faz de conta. Para o autor não importa a idade da criança e o tipo de brincadeira, estes dois aspectos sempre estarão presentes. Isidro e Almeida (2003) afirmam que as regras de uma brincadeira, ou jogo, estão intimamente ligadas ao conhecimento que as crianças têm da realidade social na qual estão inseridas.

A brincadeira, seja simbólica ou de regras, não tem apenas um caráter de diversão ou de passatempo. Pela brincadeira a criança, sem a intencionalidade, estimula uma série de aspectos que contribuem tanto para o desenvolvimento individual do ser quanto para o social (FRIEDMANN, 1996).

Primeiramente a brincadeira desenvolve os aspectos físicos e sensoriais. Os jogos sensoriais, de exercício e as atividades físicas que são promovidas pelas brincadeiras auxiliam a criança a desenvolver os aspectos referentes à percepção, habilidades motoras, força e resistência e até as questões referentes à termorregulação e controle de peso (FRIEDMANN, 1996). 
Outro fator que pode ser observado na brincadeira é o desenvolvimento emocional e da personalidade da criança. Para Friedmann (1996) as crianças têm diversas razões para brincar, uma destas razões é o prazer que podem usufruir enquanto brincam. Além do prazer, as crianças também podem, pela brincadeira, exprimir a agressividade, dominar a angústia, aumentar as experiências e estabelecer contatos sociais.

Mello (1999), em sua tese doutoral, ao estudar crianças vítimas de violência física doméstica constatou que, pela brincadeira, as crianças elaboram as experiências traumáticas vividas, pois os conteúdos expressos no brincar têm relação com suas histórias. Em conformidade com estes estudos Melo e Valle (2005), em uma discussão sobre a influência do brincar no desenvolvimento infantil, acrescentam que o brinquedo proporciona a exteriorização de medos e angústias e atua como uma válvula de escape para as emoções.

Os aspectos simbólicos de sociabilidade, linguagem e cognição também são estimulados na brincadeira. $O$ jogo é uma maneira de as crianças interagirem entre si, vivenciarem situações, manifestarem indagações, formularem estratégias e, ao verificarem seus erros e acertos, poderem reformular sem punição seu planejamento e suas novas ações (FRIEDMANN, 1996).

O jogo ao ocorrer em situações sem pressão, em atmosfera de familiaridade, segurança emocional e ausência de tensão ou perigo proporciona condições para aprendizagem das normas sociais em situações de menor risco. A conduta lúdica oferece oportunidades para experimentar comportamento que, em situações normais, jamais seriam tentados pelo medo do erro ou punição (KISHIMOTO, 1998, p. 140).

A brincadeira também é uma rica fonte de comunicação, pois até mesmo na brincadeira solitária a criança, pelo faz de conta, imagina que está conversando com alguém ou com os seus próprios brinquedos. Com isso, a linguagem é desenvolvida com a ampliação do vocabulário e o exercício da pronúncia das palavras e frases (FRIEDMANN, 1996).

A cognição e o desenvolvimento intelectual são exercitados em jogos onde a criança possa testar principalmente a relação causa-efeito. Na vida real isto geralmente é impedido pelos adultos para evitar alguns desastres e acidentes. Entretanto, no jogo ela pode vivenciar estas situações e testar as mais variadas possibilidades de ações. Suas ações interferem claramente no resultado do jogo. É necessário então que a criança passe a realizar um planejamento de estratégias para vencer o jogo (FRIEDMANN, 1996).

No jogo individual a criança pode testar as possibilidades e vontades próprias e relacioná-las com as consequências e resultados (FRIEDMANN, 1996). Quando a criança está jogando com o grupo faz-se necessário um planejamento que aproveite todas as possibilidades e que diminua as limitações existentes Além de a criança exercitar técnicas e estratégias ela também irá treinar o convívio social e as 
diversificadas formas de como lidar com os conflitos sociais que surgem durante a execução da brincadeira (ISIDRO e ALMEIDA, 2003). Outro fator positivo para o desenvolvimento é a utilização da brincadeira ou dos jogos entre pares de idades semelhantes. Para Isidro e Almeida (2003) é entre os jogos com pares semelhantes, seja na condição social ou cognitiva, que o desenvolvimento tem a sua expressão máxima.

A criança não testa diferentes estratégias apenas para o momento da brincadeira, mas também para a vida adulta. Ao lidar com diferentes situações durante a brincadeira ela estaria, sem a intencionalidade, criando condições e formas de interação que irão auxiliar mais tarde, na vida adulta.

Outros benefícios também podem ser alcançados pelo brincar. Em estudo experimental com crianças com síndrome de Down, Oliveira e Milani (2003) constataram que, as atividades lúdicas contribuem para a adequação do tônus postural, da autonomia e da capacidade de comunicação destas crianças. Pelos relatos de pesquisa expostos se percebe que a brincadeira pode ser um instrumento, utilizado por profissionais da saúde e da educação, para estimular o desenvolvimento. Uma criança que apresenta déficits em algum aspecto do desenvolvimento pode ser incentivada, através da brincadeira, a estimular estes aspectos e, como diz Vygotsky (1991) a dar saltos qualitativos no seu desenvolvimento.

\section{CONCLUSÃO}

A criança na idade escolar apresenta-se como um receptáculo, pronta para receber toda forma de estímulos exteriores em todos os níveis.

A psicologia humana afirma que crianças, independente de sua faixa etária, têm nos sentidos a forma de exploração do mundo e as experiências concretas permitem uma maior conscientização das crianças, assim atividades práticas, que movimentem e envolvam os participantes, que permitam espaços para observações e reflexões, são fundamentais para o desenvolvimento dos seus participantes.

Os jogos são versáteis, com regras flexíveis e por isso adaptam-se a todo tipo de pessoas, grupos, espaços e competências. Auxiliam na construção do conhecimento, pois ativa e desenvolve os esquemas de conhecimento que vão colaborar na aprendizagem. O jogo traz em si um espaço para proporcionar a aprendizagem partindo de uma experiência concreta, gerando uma aprendizagem ativa, porém significativa, em tempos de crescente globalização da economia e, paradoxalmente, um distanciamento radical das etnias e um crescimento do individualismo.

Brincar é coisa séria e brincar com nossas crianças é muito mais sério do que imaginávamos! Precisamos respeitar e garantir as nossas crianças o direito de brincar, de vivenciar o seu próprio desenvolvimento e entender o mundo que a cerca. 


\section{REFERÊNCIAS BIBLIOGRÁFICAS}

ALVES, R. É brincando que se aprende. Páginas Abertas. v. 27, n. 10, p. 20-21, 2001.

CORIA-SABINI, Maria Aparecida; LUCENA Regina Ferreira de. Jogos e brincadeiras na educação infantil. Campinas, SP: Papirus, 2004.

CARVALHO Alisson; SALLES Fátima; GUIMARÃES Marília. Desenvolvimento e Aprendizagem. Belo Horizonte: editora UFMG, 2002, 2ª edição.

FRIEDMANN, A. O direito de brincar: a brinquedoteca. 4를 ed. São Paulo: Abrinq, 1996.

ISIDRO, A.; ALMEIDA, A. T. M. Projecto Educar para a convivência social: O jogo no currículo escolar. Cadernos encontro: O museu a escola e a comunidade. Centro de Estudos da Criança, Universidade do Minho, Braga, 2003..

KISHIMOTO, Tizuco Morchida. Jogo, brinquedo, brincadeira e a educação. São Paulo: Cortez, 1999.

KISHMOTO, Tizuco Morchida. O jogo e a educação infantil. São Paulo: Pioneira Thomson Learning. 2002.

LEONTIEV, A. M. A brincadeira é a atividade principal da criança pequena. In: Fundação Roberto Marinho. Professor da Pré-Escola. Rio de Janeiro: FAE, 1991.

MARANHÃO, Diva Nereida Marques Machado. Ensinar Brincando: A aprendizagem pode ser uma grande brincadeira. Rio de Janeiro: Wak editora, 2003, 2ª edição.

PIAGET, Jean. A construção do real na criança. $3^{\circ}$ ed. $5^{\circ}$ reimpr. São Paulo: Ática, 2003.

VYGOTSKY, L. S. Pensamento e Linguagem. Rio de Janeiro: Martins Fontes, 1998.

VYGOTSKY, L. S. A formação social da mente. 2 ed. São Paulo: Martins Fontes, 1994.

OLIVEIRA, Vera Barros de (org). O brincar e a criança do nascimento aos seis anos. Petrópolis, RJ: Vozes, 2000.

OLIVEIRA, V. M. B.; MILANI, D. A representação lúdica e gráfica em crianças com síndrome de Down. Boletim Acadêmico Paulista de Psicologia. Vol. 23, n. 1, p. 34 $-42,2003$. 